\title{
Genome-wide markers reveal differentiation between and within the cryptic sister species, sunset and vermilion rockfish
}

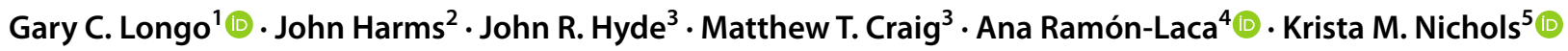

Received: 8 April 2021 / Accepted: 17 August 2021 / Published online: 5 October 2021

This is a U.S. government work and not under copyright protection in the U.S.; foreign copyright protection may apply 2021

\begin{abstract}
The vermilion rockfish complex, which consists of the cryptic sister species vermilion and sunset rockfish, is one of the most valuable recreational fisheries on the U.S. West Coast. These species are currently managed as a single complex, and because of uncertainty surrounding the relative contribution of each species within existing data sources, the stock status of each species is not fully known. A reliable and cost-effective method is needed to disentangle these species that will allow for the development of abundance indices, life history profiles, and catch histories that may potentially support species-specific stock assessments. Using restriction-site associated DNA sequence (RADseq) markers we generated 10,003 polymorphic loci to characterize the vermilion rockfish complex. PCA and Bayesian clustering approaches based on these loci clearly distinguished between sunset and vermilion rockfishes and identified hybrid individuals. These loci included 203 highly differentiated $\left(\mathrm{F}_{\mathrm{ST}} \geq 0.99\right)$ single nucleotide polymorphisms, which we consider candidates in the planned development of a diagnostic assay capable of distinguishing between these cryptic species. In addition to clearly delineating to species, subsets of the interspecific markers allowed for insight into intraspecific differentiation in both species. Population genetic analyses for sunset rockfish identified two weakly divergent genetic groups with similar levels of genetic diversity. Vermilion rockfish, however, were characterized by three distinct genetic groups with much stronger signals of differentiation and significantly different genetic diversities. Collectively, these data will contribute to well-informed, species-specific management strategies to protect this valuable species complex.
\end{abstract}

Keywords Sebastes $\cdot$ RADseq $\cdot$ Intraspecific differentiation $\cdot$ Interspecific differentiation $\cdot$ Species complex

Gary C. Longo

garycharleslongo@gmail.com

1 NRC Research Associateship Program, Northwest Fisheries Science Center, National Marine Fisheries Service, National Oceanic and Atmospheric Administration, 2725 Montlake Blvd E, Seattle, WA 98112, USA

2 Fisheries Resource Analysis and Monitoring Division, Northwest Fisheries Science Center, National Marine Fisheries Service, National Oceanic and Atmospheric Administration, 2725 Montlake Blvd E, Seattle, WA 98112, USA

3 Southwest Fisheries Science Center, National Marine Fisheries Service, National Oceanic and Atmospheric Administration, 8901 La Jolla Shores Drive, La Jolla, CA 92037, USA
4 University of Washington CICOES Program at Northwest Fisheries Science Center, National Marine Fisheries Service, National Oceanic and Atmospheric Administration, 2725 Montlake Blvd E, Seattle, WA 98112, USA

5 Conservation Biology Division, Northwest Fisheries Science Center, National Marine Fisheries Service, National Oceanic and Atmospheric Administration, 2725 Montlake Blvd E, Seattle, WA 98112, USA 


\section{Introduction}

The genus Sebastes (Scorpaeniformes:Sebastidae) is a rapidly evolving lineage of marine fishes that includes many commercially and recreationally important species. Although Sebastes can be found in temperate regions of the North Atlantic and southern hemisphere, the greatest diversity is found in the North Pacific (Hyde and Vetter 2007; Love et al. 2002). In the North Pacific, the genus has been characterized as an adaptive radiation with rapid diversification into heterogeneous ecological niches and habitats that often occur along a depth gradient (Heras and Aguilar 2019; Hyde and Vetter 2007; Ingram 2011; Johns and Avise 1998; Love et al. 2002). In such rapidly diverging lineages, the true extent of species diversity can be underestimated as some closely related taxa may be difficult to differentiate morphologically. Indeed, genetic studies within Sebastes have uncovered several cryptic species pairs including $S$. aleutianus and S. melanostictus (Gharrett et al. 2005; Orr and Hawkins 2008), S. mystinus and S. diaconus (Burford and Bernardi 2008; Frable et al. 2015) and S. miniatus type I and type II (Hyde et al. 2008a, b; Hyde and Vetter 2007). The identification of cryptic species complexes such as these, which clearly represent distinct taxonomic units, is critical to effective fisheries management. Although closely related, sister taxa can often be characterized by dissimilar life history traits, abundances and productivity. For instance, in the rougheye rockfish species complex, S. aleutianus and $S$. melanostictus exhibit significantly different reproductive parameters (Conrath 2017). These parameters are vital for accurate stock assessment models and the estimation of stock biomass. In cases such as this, treating distinct taxa as a single complex may present significant risk to one or both species and place them at risk of overfishing (Burford et al. 2011; Frable et al. 2015; Hyde and Vetter 2009).

The vermilion rockfish species complex, which includes the vermilion rockfish ( $S$. miniatus) and the yet to be formally described sunset rockfish ( $S$. miniatus type I sensu Hyde et al., 2008a, b), is of particular concern as it is one of the most valuable recreational fisheries on the U.S. West Coast. These sister species, which diverged around 2.3 Ma (Hyde and Vetter 2007), show a high degree of range overlap from central California to northern Baja, Mexico but exhibit dissimilar depth distribution as adults. Vermilion rockfish are more common in shallower waters $(<100 \mathrm{~m})$ in kelp forest habitat while sunset rockfish are typically found deeper $(>100 \mathrm{~m})$ at offshore banks (Hyde et al. 2008a, b; Love and Passarelli 2020). The vermilion complex is the third-most commonly landed recreational species of groundfish on the U.S. West Coast with approximately $625 \mathrm{mt}$ of landings in 2019 (RecFIN extracted 1 Feb 2021) and forms a critical component of the coast's recreational fishery that contributed over $\$ 1.8$ billion to the region's GDP based on the most recent estimate prepared in 2014 (Lovell et al. 2016). The stock status of both sister species are not fully known as previous attempts to assess the assemblage in 2005 and 2013 were not endorsed for setting harvest guidelines by the Pacific Fishery Management Council (PFMC) in part because of uncertainty surrounding the relative contribution of each species within existing data sources.

NOAA's Northwest Fisheries Science Center (NWFSC) annually conducts a bottom trawl survey and a hook and line survey along the U.S. West Coast that, along with multiple other sources, has acquired thousands of tissue samples nominally identified as vermilion rockfish with associated biological and environmental data (Harms et al. 2008; Keller et al. 2017). Providing a reliable method to disentangle sunset and vermilion rockfish will allow for the development of separate abundance indices, life history profiles, and, potentially, catch histories to support the assessment of this commercially and recreationally important species complex. ${ }^{1}$

Previous efforts to delineate the vermilion rockfish complex to species using mitochondrial DNA (mtDNA) alone yielded inconclusive results due to a historical one-way mitochondrial introgression of vermilion rockfish-type haplotypes into sunset rockfish populations (Hyde et al. 2008a, b). Specifically, a portion of sunset rockfish are characterized by vermilion rockfish mitochondrial haplotypes and sunset rockfish nuclear genotypes, and are referred to here as introgressed sunset rockfish. Although microsatellite markers have proven effective for disentangling this species complex (Hyde and Budrick, unpublished data), this approach remains costly and is not well suited to the scale of samples that must be genotyped $(\sim 25,000)$ to achieve a suitable dataset for stock assessment purposes. An attractive alternative is the use of a high-throughput approach, such as restriction site-associated DNA sequencing (RADseq), that can identify thousands of genome-wide markers and potentially diagnostic single nucleotide polymorphisms (SNPs). With proper primer design, diagnostic SNPs can be incorporated into an assay, such as a Genotyping-in-Thousands by sequencing (GTseq) panel (Campbell et al. 2015), that provides a cost-effective assignment method (Larson et al. 2014; McKinney et al. 2020). Such an approach in the vermilion rockfish complex would allow for species-specific demographic and biological analyses to be carried out with the thousands of samples already collected. Additionally, RADseq has proven to be an effective tool in identifying and assessing intraspecific differentiation, especially in

\footnotetext{
1 Vermilion and sunset rockfish are scheduled for a stock assessment in 2021 under the auspices of the PFMC where the two species will be assessed collectively as a complex.
} 
cases where traditional markers (i.e., mtDNA and microsatellites) failed to detect signals of structure (Bohling et al. 2019; Gaither et al. 2020; Longo et al. 2020; Morgan et al. 2018; Vaux et al. 2021; Vendrami et al. 2019). Although distinguishing between clear taxonomic units at the level of species is paramount, the identification of significant intraspecific population genetic structure is also important for species-specific management (Bernatchez et al. 2017; Hauser and Seeb 2008; Spies and Punt 2015; Waples et al. 2008). Furthermore, an understanding of population genetic structure allows for insight into the ecological and evolutionary processes shaping differentiation (Bradbury et al. 2008; DeWoody and Avise 2000; Martinez et al. 2018; Romiguier et al. 2014). Previous population genetic work on vermilion rockfish revealed significant population structure and detailed how a shift in ontogenetic migratory behavior in conjunction with oceanographic conditions likely resulted in the observed differentiation (Budrick 2016; Hyde and Vetter 2009). Past population genetic work on sunset rockfish, however, did not detect intraspecific differentiation although the study used a limited number of sampling sites (Budrick 2016). Clearer insight into the population genetic structure of sunset and vermilion rockfishes, respectively, will allow for more informed, species-specific stock assessment and management strategies, and may further the understanding of the mechanisms driving diversification in the Sebastes species flock.

In this study we used RADseq markers to assess the degree of interspecific differentiation between sunset and vermilion rockfishes, and also evaluated and compared population differentiation within each species. With these loci we also identified diagnostic SNPs for the future development of an assay capable of distinguishing between these cryptic species. Our results shed additional light on how life history variation may affect past and ongoing speciation processes in the speciose Sebastes rockfishes.

\section{Methods}

\section{Sample selection, RADseq library preparation, data filtering, and genotype calling}

We utilized samples collected from the NWFSC's Southern California Shelf Rockfish Hook and Line Survey and West Coast Groundfish Bottom Trawl Survey, as well as opportunistically collected samples from the Southwest Fisheries Science Center's tissue archive that were previously identified as vermilion rockfish, sunset rockfish, or as introgressed sunset rockfish based on nuclear and/or mtDNA data (Hyde et al. 2008a, b; Hyde and Vetter 2009; Unpublished data; Table S1). These samples also included "indeterminates" that could not be confidently assigned to one of the aforementioned groups due to inconclusive molecular results but were suspected sunset rockfish, suspected vermilion rockfish, or suspected sunset/vermilion hybrids. Additionally, we assessed samples previously identified only by vermilion rockfish-type mitochondrial haplotypes, which could either be introgressed sunset rockfish or vermilion rockfish due to a past, one-way introgression event (Hyde et al. 2008a, b). Collectively, 388 samples were selected for extraction that were collected from Central Baja, Mexico ( $29.2^{\circ}$ latitude) to the Strait of Juan de Fuca, Washington ( $\sim 8.4^{\circ}$ latitude) and from depths ranging from 44 to $314 \mathrm{~m}$. Genomic DNA was extracted from fin clips stored in $95 \%$ ethanol or dried fin punches using the Qiagen DNAeasy Blood \& Tissue 96 extraction kit (Qiagen, Inc., Valencia, CA) and then quantified using a BioTek FLX800 Microplate Fluorescence Reader. Samples with extractions yielding $<12.5 \mathrm{ng} / \mu 1$ were not sequenced. Individual DNA concentrations for the 288 remaining samples were normalized to $12.5 \mathrm{ng} / \mu \mathrm{l}$ and $125 \mathrm{ng}$ of starting material was used for RADseq library prep. We used the RADseq protocol of Ali et al. (2016) to construct libraries with the following specific details: (1) genomic DNA from each sample was digested with the restriction enzyme SbfI; (2) libraries were sheared to 300-500 bp using a Qsonica sonicator (Newton, CT); and, (3) 100 bp paired-end sequencing was conducted in 3 lanes using a HiSeq 4000 (Illumina, Inc., San Diego, CA) at the University of Oregon Genomics and Cell Characterization Core Facility (GC3F, Eugene, Oregon).

We ran Stacks v2.4 (Catchen et al. 2013) components individually in a de novo analysis to discover and identify SNPs from raw sequence data. Raw sequence data were quality filtered, demultiplexed, trimmed to $85 \mathrm{bp}$, and filtered for PCR clones using the programs process_radtags and clone_filter. We followed methods outlined in Paris et al. (2017) and Rochette and Catchen (2017) to determine the optimal Stacks parameters specific to our dataset to minimize erroneous splitting or lumping of loci while simultaneously yielding a high number of polymorphic loci. Specifically, 12 high coverage individuals that included vermilion, sunset and introgressed sunset rockfish were used for optimization, and three was found to be the optimal value both for the maximum number of bp differences between alleles in a sample $(-M)$ and the maximum number of bp mismatches between sample loci $(-n)$. After initial trimming and filtering for low quality reads and PCR clones, loci were identified in each individual using ustacks with a minimum allele depth $(-m)$ of three. A catalog of consensus loci was constructed with cstacks using 46 high coverage individuals (i.e., ustacks mean coverage $\geq 35 \mathrm{x}$ ) that included vermilion rockfish, sunset rockfish, and introgressed sunset rockfish. Stacks was then used to match individual sample loci to the catalog. Prior to running populations, we excluded individuals with 
ustacks mean coverage $<15 \times$ resulting in 242 individuals. Within populations, loci were dropped that failed to meet the following criteria: present in $\geq 80 \%$ of individuals, minor allele count (MAC) $\geq 3$, and maximum observed heterozygosity of $70 \%$. We exported the resulting SNP dataset from Stacks and further filtered using VCFtools v0.1.13 (Danecek et al. 2011). We then dropped all but the first SNP from each RADseq locus (- thin 5000), removed loci in individuals that were below $10 \times$ depth of coverage ( $-\min D P 10)$, refiltered for loci found in $\geq 80 \%$ of individuals (- max-missing 0.8 ), removed individuals with $>30 \%$ missing loci the (- remove), and again filtered for loci with a MAC $\geq 3$ (- mac 3$)$ in the final dataset, which was exported for downstream analyses. Finally, we checked for duplicate individuals using a custom $\mathrm{R}$ script written by Garrett McKinney (https://github.com/gjmck inney/IDduplicateSamples).

\section{Interspecific analyses}

\section{Differentiation analyses}

To assess interspecific differentiation and identify hybridization/introgression, we ran genetic structure analyses without any a priori assumptions about species boundaries. We used a model-based Bayesian clustering analysis implemented in STRUCTURE v2.3.4 (Pritchard et al. 2000) where ten replicates were run for each number of genetic clusters tested $(K=1-10)$, each with a burn-in of 10,000 iterations and 100,000 MCMC replicates with admixture allowed (NOADMIX $=0$ ) and no prior location information (LOCPRIOR $=0$ ). Next, we assessed the most likely number of clusters $(\mathrm{K})$ across replicate runs using the Evanno method (Evanno et al. 2005), which assesses the rate of change in log probability of the data between successive values of $\mathrm{K}(\Delta \mathrm{K})$ as implemented in Structure Harvester (Earl and vonHoldt 2012). We also used the mean likelihood of the model $[\mathrm{L}(\mathrm{K})]$ for evaluating $\mathrm{K}$ as the Evanno method cannot detect a scenario of $\mathrm{K}=1$. Finally, CLUMPP v1.1.2 (Jakobsson and Rosenberg 2007) was used to summarize results across replicate STRUCTURE runs and final plots were created in $\mathrm{R}$ with ggplot (Wickham 2016). Average individual membership coefficients ( $Q$ values) to each cluster were taken from CLUMPP for species assignment. Additionally, we also used principal component analysis (PCA) to summarize the diversity and variation across RADseq loci using the $\mathrm{R}$ package adegenet $\mathrm{v} 2.1 .3$ (Jombart 2008; Jombart et al. 2010). In the PCA, missing data were replaced by the mean allele frequencies with option NA.method= "mean" in the scaleGen() function and the number of principal components kept was determined using a scree plot of eigenvalues.

\section{Identification of diagnostic loci}

In order to confidently identify RADseq loci that unambiguously distinguish between sunset and vermilion rockfishes, apparent hybrids (i.e., Q values $>20 \%$ admixture) and clear misidentifications (based on PCA and STRUCTURE results) were removed and the dataset was refiltered in VCFtools for a MAC $\geq 3$ prior to downstream analyses. Specifically, PC 1 from the interspecific PCA was used to classify individuals into species groups. Individuals previously identified as vermilion rockfish, indeterminate vermilion rockfish, or as vermilion or introgressed sunset rockfish with a PC 1 score of $<-40$ were placed in the vermilion rockfish group. Individuals previously identified as sunset rockfish, introgressed sunset rockfish, indeterminate sunset rockfish or as vermilion or introgressed sunset rockfish with a PC 1 score $>40$ were placed in the sunset rockfish group (see Table S1 for sample nomenclature specifics). We then calculated locusspecific F-statistics and overall $\mathrm{F}_{\mathrm{ST}}$ (Weir and Cockerham 1984) between sunset rockfish and vermilion rockfish groups using the R package HIERFSTAT (Goudet 2005). Highly differentiated (i.e., $\mathrm{F}_{\mathrm{ST}} \geq 0.99$ ) loci with SNPs $>20$ bp from the $5^{\prime}$ end (to allow for primer design in later amplicon panels) were considered as candidates for diagnostic panel development. We report the number of high-quality candidate markers here but the details of primer design and panel testing will be discussed in subsequent work.

\section{Intraspecific analyses}

The interspecific dataset—post removal of the admixed and misidentified individuals, and subsequent MAC $\geq 3$ filterwas used as a starting point to evaluate population structure and diversity within species. Individuals from this dataset were split into sunset rockfish-specific and vermilion rockfish-specific datasets based on the criteria described above in the "Identification of diagnostic loci" section. Within the respective vermillion and sunset rockfish datasets, nonpolymorphic loci were dropped using a MAC $\geq 3$ filter in VCFtools. The following analyses were then carried out on each species-specific dataset independently.

\section{Population structure and genetic analyses}

PCA and STRUCTURE analyses were run using the methods described above in the "Interspecific differentiation analyses" section. PCA groupings and STRUCTURE assignment results were then used to designate groups for population genetic analyses. Individuals that showed signs of admixture among populations were excluded from downstream 
Fig. 1 Principal component analysis on 10,003 interspecific SNPs from 231 samples previously identified (based on nuclear and/or mtDNA data) as vermilion rockfish, indeterminate vermilion rockfish, vermilion or introgressed sunset rockfish, indeterminate hybrid, sunset rockfish, introgressed sunset rockfish, and indeterminate sunset rockfish

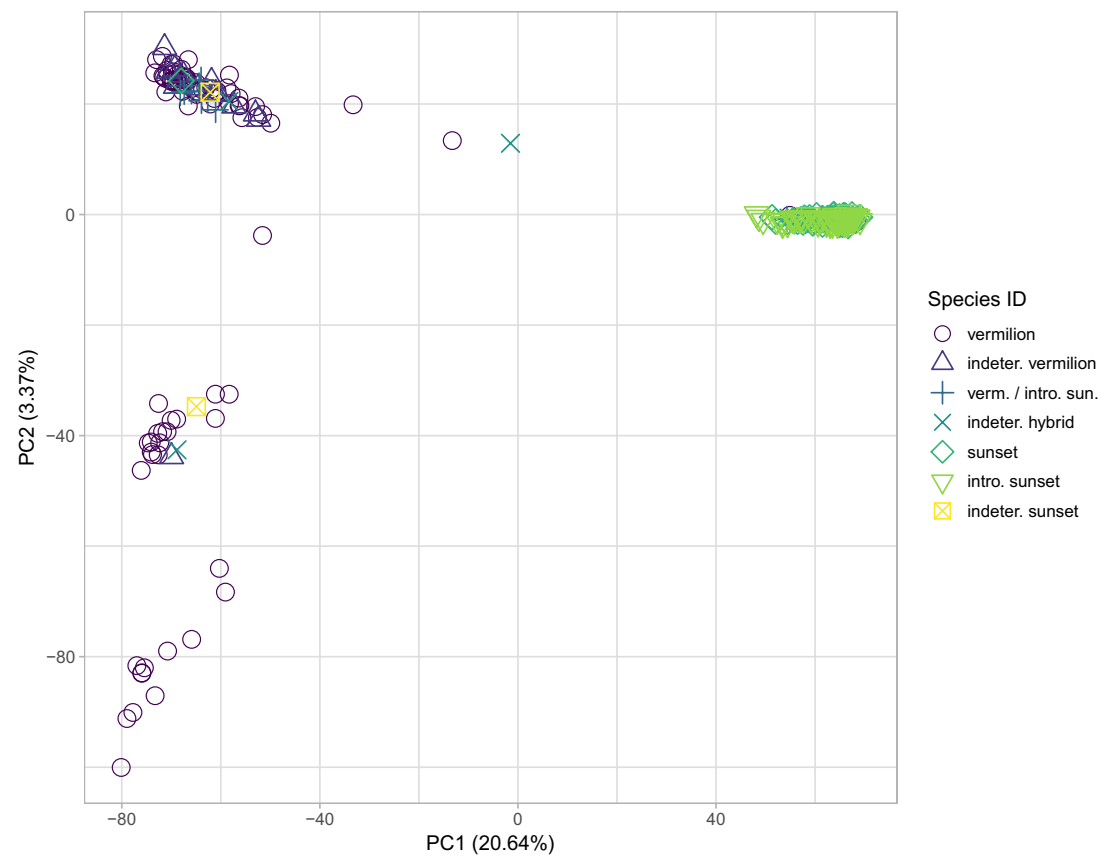

analyses as there was no a priori knowledge of population boundaries. Individual sampling sites were mapped using ggplot2 v3.3.3 (Whickham, 2016) and marmap v1.0.4 (Pante and Simon-Bouhet 2013).

Mean and locus-specific genetic diversity indices, global and locus-specific F-statistics, and population pairwise $\mathrm{F}_{\mathrm{ST}}$ (Weir and Cockerham 1984) were calculated using the $\mathrm{R}$ package HIERFSTAT v0.04-30 (Goudet 2005). Also in HIERFSTAT, we used boot.vc to calculate $95 \%$ confidence intervals (CI) for the global F-statistics, and used boot.ppfst to test and infer significance for pairwise $\mathrm{F}_{\mathrm{ST}}$ comparisons when confidence intervals of 1000 bootstrap replicates did not overlap with zero. We computed the expected heterozygosity within populations $\left(\mathrm{H}_{\mathrm{S}}\right)$ and tested if differences between populations were significant using 999 permutations with $H_{S}$ and Hs.test, respectively, in adegenet v2.1.3 (Jombart 2008).

\section{Results}

Stacks filtering parameters on the entire interspecific dataset resulted in 35,910 total RADseq markers, including monomorphic loci. Using VCFtools, we retained only the first SNP on each polymorphic marker, which reduced the data set to 24,026 SNPs. Subsequent filtering for $\geq 10 \times$ coverage for each locus of every individual and for loci found in $\geq 80 \%$ of individuals dropped the number of loci to 10,159 . After individuals with more than $30 \%$ missing loci were removed, 231 individuals remained. Finally, after filtering for a $\mathrm{MAC} \geq 3,10,003$ polymorphic loci were retained for interspecific analyses. No duplicate individuals were detected (see Tables S2, S3, \& S4 for filtering steps and SNP dataset depth qualities).

\section{Interspecific results}

The scree plot for the interspecific PCA based on 10,003 polymorphic loci suggested the first three eigenvalues best explained the variation (Fig. S1). Principal component 1, which explained $20.64 \%$ of the variation, showed a clear distinction between sunset and vermilion rockfishes. Although sunset rockfish showed little intraspecific variation in this interspecific PCA, vermilion rockfish showed clear intraspecific variation with three distinct groupings separated by both PC2, which explained $3.37 \%$ of the variation (Fig. 1), and PC3, which explained $1.11 \%$ of the variation (Fig. S2). Replicate STRUCTURE runs overwhelmingly suggested $K=2$ as the most likely scenario based on $(\Delta K)$, while $[\mathrm{L}(\mathrm{K})]$ strongly suggested that $\mathrm{K}=1$ is the least likely scenario (Table S5). The $\mathrm{K}=2$ plot shows that sunset and vermilion rockfishes are clearly differentiated from each other in most cases (Fig. 2). However, both PCA and STRUCTU $R E$ analyses revealed 12 individuals that were either mislabeled or misidentified (e.g., 3 of the 4 indeterminate hybrids clearly grouped with either vermilion or sunset rockfish), as well as three individuals that represent likely hybrids (i.e., one indeterminate hybrid and two individuals previously identified as vermilion; Figs. 1, 2). These individuals were not included in either sunset or vermilion groups for detecting diagnostic SNPs and were also excluded from subsequent intraspecific analyses. Although individuals with 


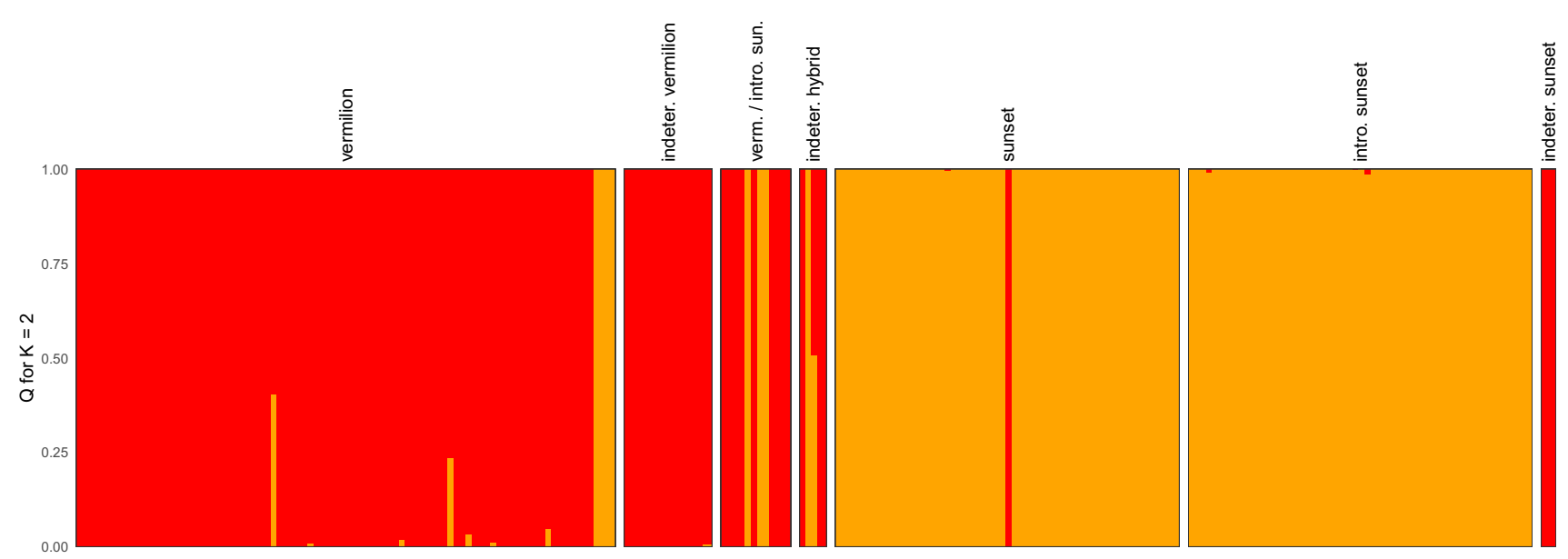

Fig. 2 Bayesian clustering results from STRUCTURE $(K=2)$ for all 231 samples and 10,003 loci. Individuals are arranged based on previous molecular identification (nuclear and/or mtDNA data) from vermilion rockfish, indeterminate vermilion rockfish, vermilion or introgressed sunset rockfish, indeterminate hybrid, sunset rockfish, introgressed sunset rockfish, to indeterminate sunset rockfish

Fig. 3 Principal component analysis for sunset rockfish based on 5,043 intraspecific SNPs reveal two distinct groupings, S-A and S-B. Individual sampling latitude is shown by color and mitochondrial haplotypes are depicted by shape

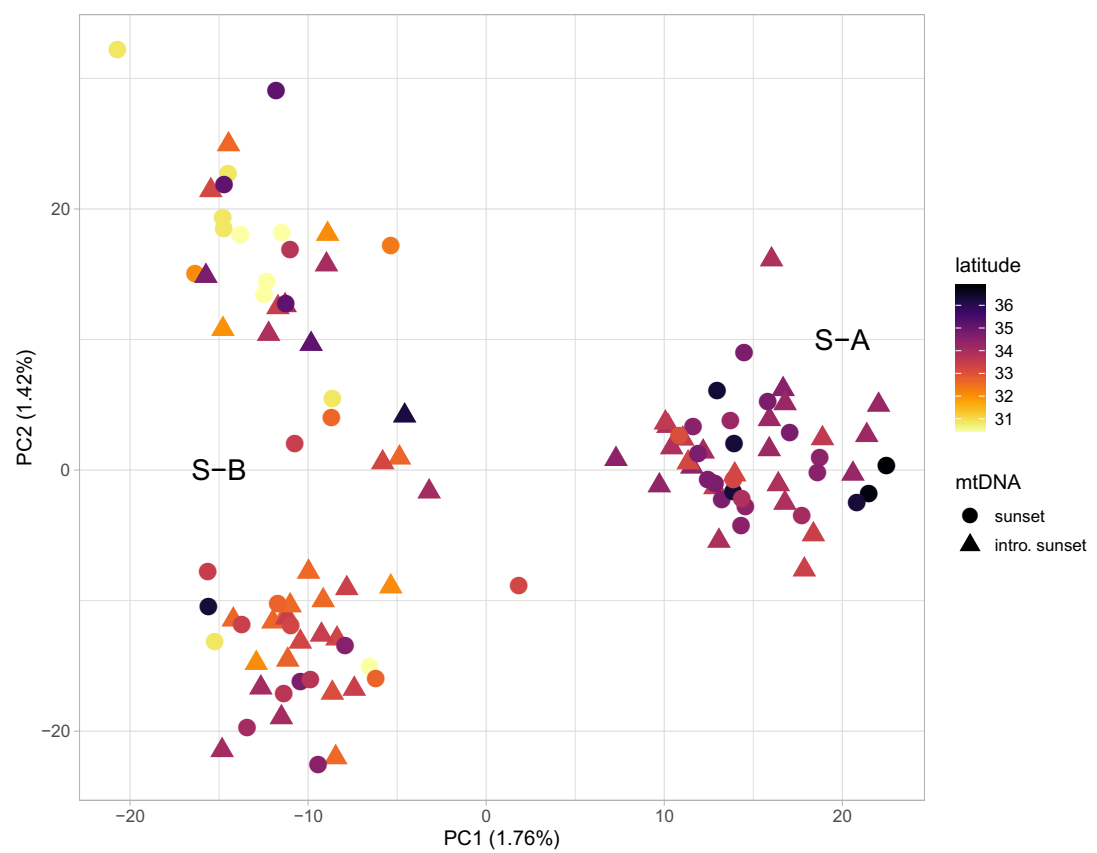

low levels of admixture were rare, the direction of nuclear introgression was more commonly from sunset rockfish into vermilion rockfish (Fig. 2).

\section{Interspecific F-statistics and diagnostic loci}

Sunset and vermilion rockfishes showed strong overall differentiation with an $\mathrm{F}_{\mathrm{ST}}=0.5478(0.5382-0.557595 \% \mathrm{CI})$. We detected 203 highly differentiated (i.e., $\mathrm{F}_{\mathrm{ST}} \geq 0.99$ ) SNPs located $>20$ bp from the $5^{\prime}$ end of their respective RADseq paired-end contig sequence, 117 of which were fixed $\left(\mathrm{F}_{\mathrm{ST}}=1\right)$. Further testing is required but these loci appear to be promising candidates for developing a diagnostic SNP assay to distinguish sunset and vermilion rockfish.

\section{Sunset rockfish}

One hundred fourteen individuals were assigned to sunset rockfish. Removal of non-polymorphic loci using a MAC $\geq 3$ filter resulted in 5043 loci.

\section{Population genetic results}

The scree plot for the PCA based on the filtered sunset rockfish dataset suggested the first two eigenvalues best 

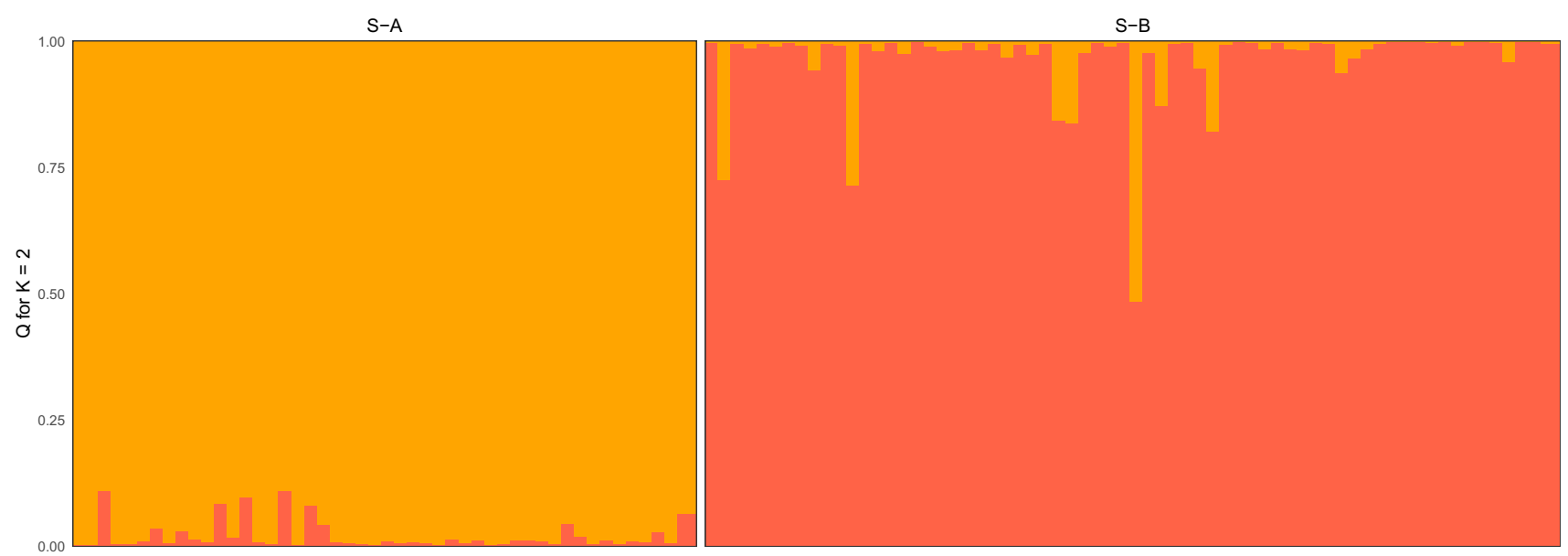

Fig. 4 Bayesian clustering results from STRUCTURE $(\mathrm{K}=2)$ for sunset rockfish based on 5,043 intraspecific SNPs. Individuals are arranged based on distinct PCA groupings, S-A and SB

explained the variation (Fig. S3). The PCA plot showed two groups separated along PC1 (1.76\% of the variation), which we refer to as S-A (PC1 $>5)$ and S-B (PC1 <0; Fig. 3). Replicate STRUCTURE runs corroborate the PCA pattern, with both $\Delta \mathrm{K}$ and $[\mathrm{L}(\mathrm{K})]$ finding $\mathrm{K}=2$ as the most likely scenario (Table S6). Most individuals clearly assigned to one of the two clusters $(\mathrm{Q}>0.7)$, however, one individual showed signs of significant admixture with $\mathrm{Q}$ assignment values of $\sim 0.52 / 0.48$ to Group S-A and S-B, respectively (Fig. 4). This individual was excluded from population genetic analyses resulting in 113 individuals total (48 and 65 individuals in S-A and S-B, respectively).

Individuals with introgressed and non-introgressed mitochondrial haplotypes-vermilion and sunset rockfish mtDNA, respectively - were found in near equal numbers in both S-A (25:23) and S-B (34:31; Fig. 3). Individuals in S-A and S-B showed a difference in depth of capture (Fig. S4A) with S-B being more common in intermediate depths while S-A was more common at shallower and deeper depths. When each sunset group was separated by mitochondrial haplotype, introgressed haplotypes were generally more common in more shallow habitat while non-introgressed haplotypes were relatively common throughout sampling depths (Fig. S4B). Notably, S-A and S-B groups appeared to show differences in latitudinal distribution in the PCA (Fig. 3). More specifically, when individual sunset rockfish geographic coordinates were mapped, S-A individuals were found in higher latitudes in close proximity to the coast while S-B individuals dominated the lower latitudes on the offshore banks and islands of the Southern California Shelf (Fig. 5).

Population genetic diversity, as estimated by expected heterozygosity $\left(\mathrm{H}_{\mathrm{S}}\right)$, was similar but slightly lower in S-A compared to S-B (0.2123 and 0.2138 , respectively) but not significantly different from each other $(p=0.185)$. Global F-statistics and mean genetic diversities for sunset rockfish are reported in Table 1. Pairwise $\mathrm{F}_{\mathrm{ST}}$ comparison (between S-A and S-B) yielded a significant value of 0.0122 , which was identical to the reported global $\mathrm{F}_{\mathrm{ST}}$, as expected. Locusspecific estimates of observed heterozygosity, within population gene diversity, overall gene diversity, gene diversity among samples, fixation index, inbreeding coefficient, and Jost's measure of population differentiation (Jost's D) are reported in Table S7. Sunset rockfish locus-specific corrected $\mathrm{F}_{\mathrm{ST}}\left(\mathrm{F}_{\mathrm{STP}}\right)$ values ranged from -0.0215 to 0.5564 .

\section{Vermilion rockfish}

One hundred five individuals were assigned as vermilion rockfish. Removal of non-polymorphic loci using a MAC $\geq 3$ filter resulted in 6406 loci.

\section{Population genetic results}

The scree plot for the PCA based on the filtered vermilion rockfish dataset suggested the first two eigenvalues best explained the variation (Fig. S5). The PCA plot showed three distinct groups separated along both PC1 $(8.05 \%$ of the variation) and $\mathrm{PC} 2(2.38 \%$ of the variation $)$, which we refer to as V-A (PC1 > 45), V-B (PC2>20), and V-C (PC1<-10; Fig. 6). Replicate STRUCTURE runs show similar patterns of differentiation with $\Delta \mathrm{K}$ suggesting that $K=2$ was the most likely scenario followed by $K=3$, while $[\mathrm{L}(\mathrm{K})]$ suggested $\mathrm{K}=3$ was slightly more likely than $\mathrm{K}=2$ (Table S8). Plots for both $\mathrm{K}=2$ and $\mathrm{K}=3$ corroborate the PCA pattern with three distinct cluster assignment groups (Fig. 7). Both PCA and STRUCTURE identify an individual that showed significant admixture between groups V-B and 
Fig. 5 Individual sunset rockfish sampling locations withs colors corresponding to associated intraspecific grouping, S-A and S-B

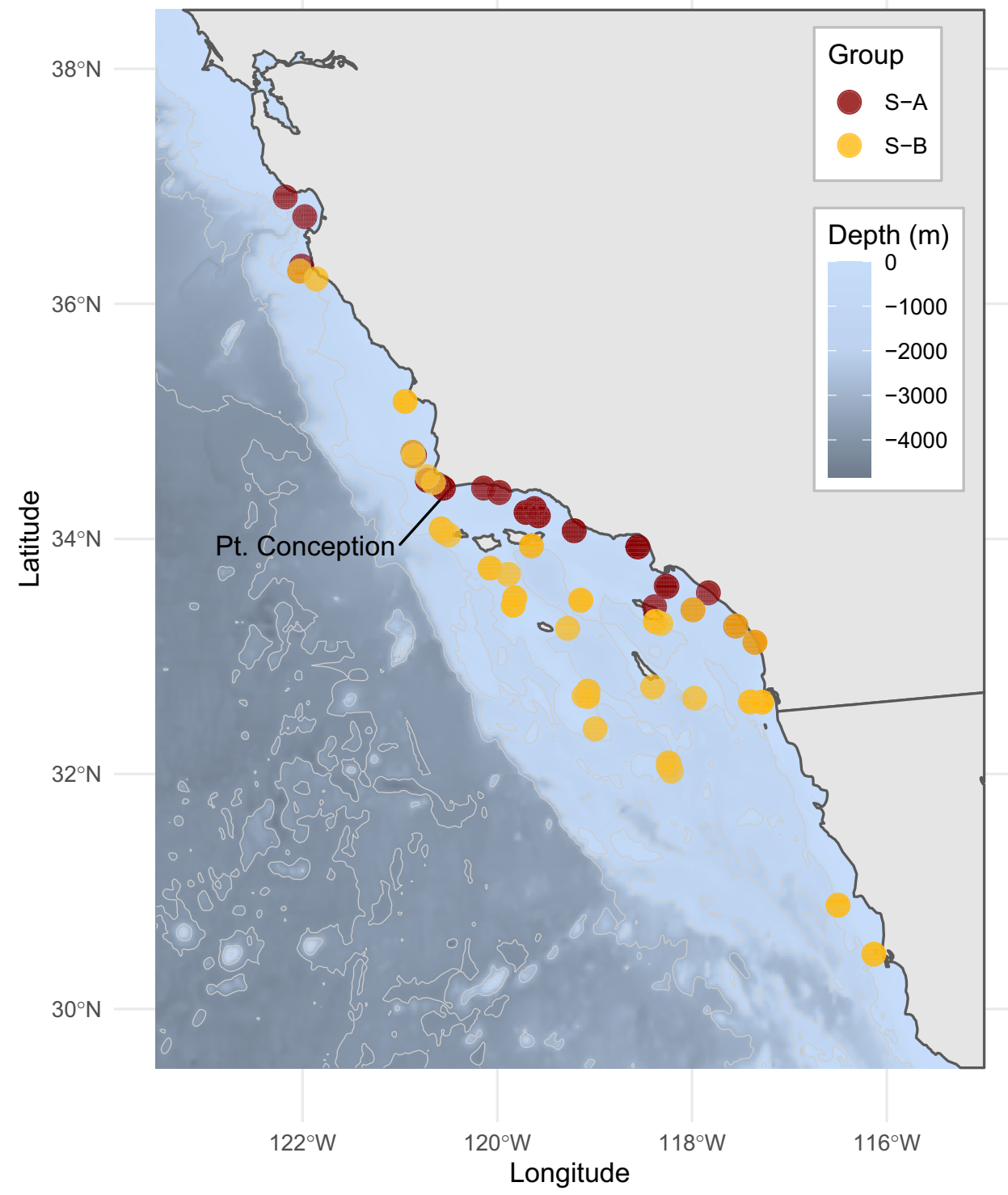

Table 1 Intraspecific global F-statistics (95\% CI) and diversity indices for sunset rockfish and vermilion rockfish based on 5403 and 6406 SNPs, respectively

\begin{tabular}{lllllll}
\hline Species & $\mathrm{F}_{\mathrm{ST}}$ & $\mathrm{F}_{\mathrm{IS}}$ & $\mathrm{F}_{\mathrm{IT}}$ & $\mathrm{H}_{\mathrm{O}}$ & $\mathrm{H}_{\mathrm{S}}$ & $\mathrm{H}_{\mathrm{T}}$ \\
\hline Sunset & $0.0122(0.0109-0.0136)$ & $0.0852(0.0798-0.0908)$ & $0.0964(0.0906-0.1018)$ & 0.1972 & 0.2155 & 0.2168 \\
Vermilion & $0.1641(0.1587-0.1715)$ & $0.0927(0.0881-0.0975)$ & $0.2416(0.2349-0.2497)$ & 0.1725 & 0.1925 & 0.217 \\
\hline
\end{tabular}

V-C (Figs. 6,7). This individual was excluded from population genetic analyses resulting in 104 individuals total (12, 17 , and 75 individuals in $\mathrm{V}-\mathrm{A}, \mathrm{V}-\mathrm{B}$, and $\mathrm{V}-\mathrm{C}$, respectively).

Depth of capture was not plotted for vermilion rockfish groups as these data were lacking for all V-A individuals and only available for 3 out $17 \mathrm{~V}$-B individuals. Geographic coordinates, however, were available for all samples and, like sunset rockfish groups, vermilion rockfish groups showed a difference in latitudinal distribution in the PCA (Fig. 6). Specifically, when vermilion rockfish individuals were mapped, $\mathrm{V}$-A individuals were restricted to higher latitudes north of Point Reyes, CA, V-B individuals were common in Central California from Cape Mendocino south to Point Conception, and V-C individuals dominated south of Point Conception but were relatively rare to the north (Fig. 8). Notably, V-B was absent from the Southern California Shelf but was 
Fig. 6 Principal component analysis for vermilion rockfish based on 6406 intraspecific

SNPs reveal three distinct groupings, V-A, V-B, and V-C Individual sampling latitude is shown by color

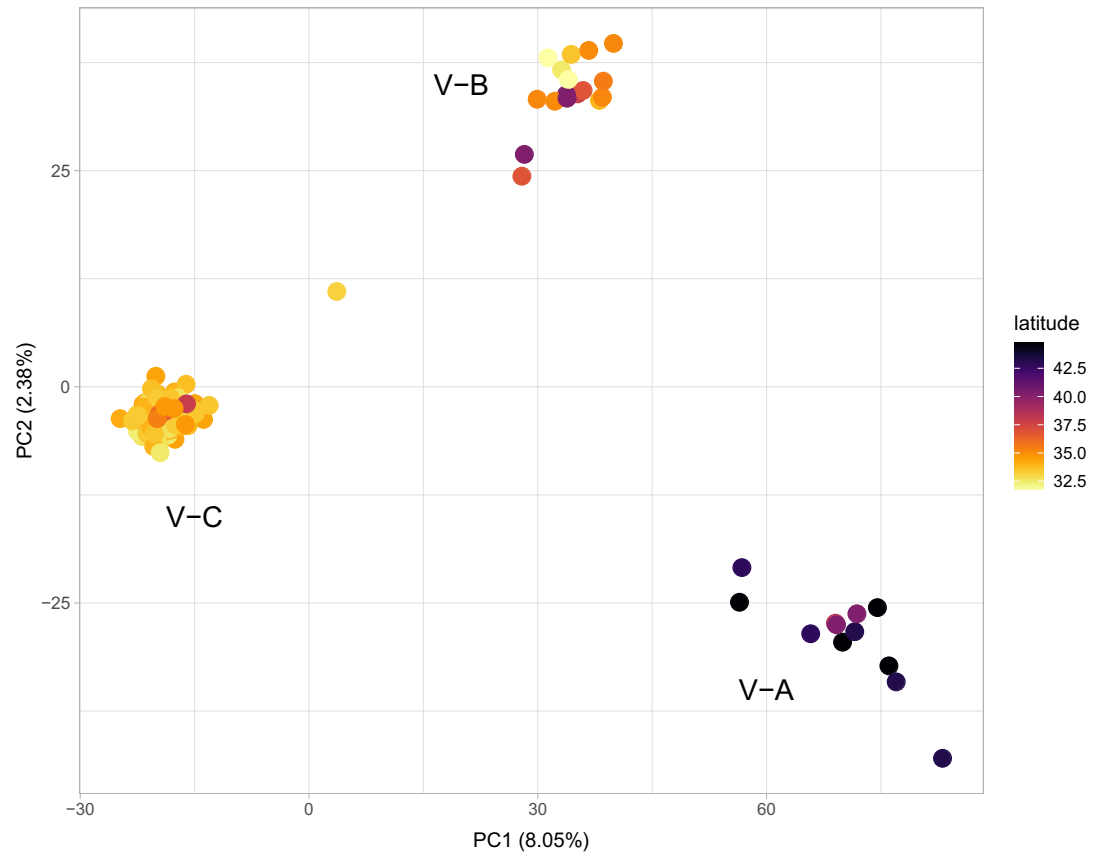

$\mathrm{V}-\mathrm{C}$

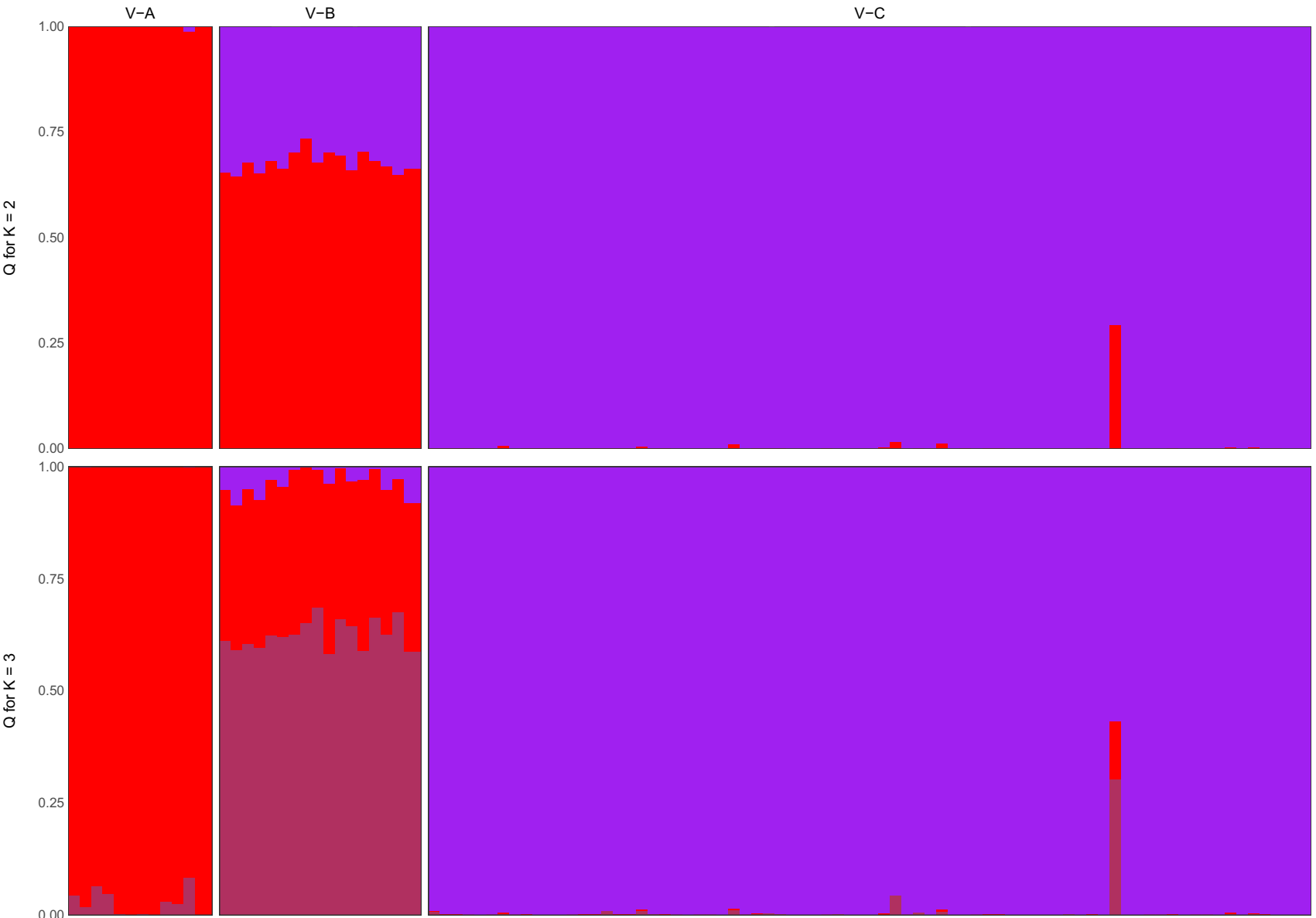

Fig. 7 Bayesian clustering results from STRUCTURE for vermilion rockfish based on 6,406 intraspecific SNPs for $\mathrm{K}=2$ and $\mathrm{K}=3$. Individuals are arranged based on distinct PCA groupings, V-A, V-B, and V-C 


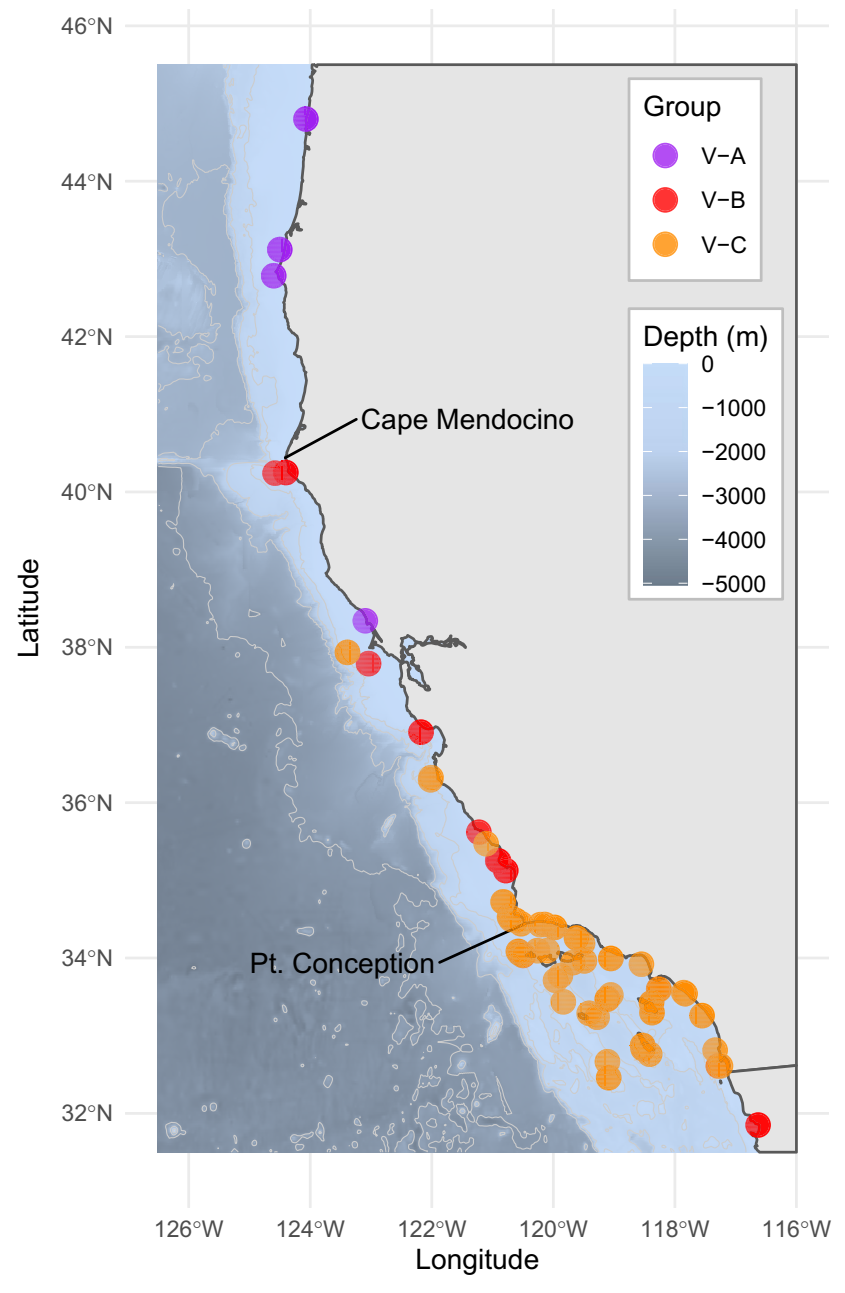

Fig. 8 Individual vermilion rockfish sampling locations withs colors corresponding to associated intraspecific PCA grouping, V-A, V-B, and V-C (Note: the southernmost V-B was opportunistically sampled from the Mercado Negro fish market in Ensenada, Baja California, Mexico)

sampled at the Mercado Negro fish market in Ensenada, Baja California, Mexico. However, this is the largest fish market in Baja and these Group B individuals may have been caught at a distant location.

Population genetic diversities, as estimated by expected heterozygosity $\left(\mathrm{H}_{\mathrm{S}}\right)$, for $\mathrm{V}-\mathrm{A}, \mathrm{V}-\mathrm{B}$, and $\mathrm{V}-\mathrm{C}$ were 0.1618 , 0.1939 , and 0.2026 , respectively, and were significantly different from each other in all three comparisons ( $\mathrm{p}=0.001$ for $\mathrm{V}-\mathrm{A} / \mathrm{V}-\mathrm{B}$ and $\mathrm{V}-\mathrm{A} / \mathrm{V}-\mathrm{C}, \mathrm{p}=0.024$ for $\mathrm{V}-\mathrm{B} / \mathrm{V}$ C). Notably, $\mathrm{H}_{\mathrm{S}}$ was highest in $\mathrm{V}-\mathrm{C}$, the southernmost group, and progressively decreased to the north in V-B and V-A. Mean genetic diversities and global F-statistics with $95 \%$ CI for vermilion rockfish are reported in Table 1. Pairwise $\mathrm{F}_{\mathrm{ST}}$ comparisons between V-A and V-B, V-A and $\mathrm{V}-\mathrm{C}$, and V-B and V-C were $0.1099,0.2326$, and 0.1147, respectively; all comparisons were significant. Locusspecific estimates of observed heterozygosity, within population gene diversity, overall gene diversity, gene diversity among samples, fixation index, inbreeding coefficient, and Jost's D are reported in Table S9. Vermilion rockfish locus-specific corrected $\mathrm{F}_{\mathrm{ST}}\left(\mathrm{F}_{\mathrm{STP}}\right)$ values ranged from -0.0695 to 0.8977 . Locus-specific metrics were estimated for each pairwise comparison between nominal vermilion rockfish groups ad hoc in order to potentially detect loci with fixed differences (i.e., $\mathrm{F}_{\mathrm{ST}}=1$ ). No fixed differences were detected between $\mathrm{V}-\mathrm{B}$ and $\mathrm{V}-\mathrm{C}$, however five were detected between $\mathrm{V}-\mathrm{A}$ and $\mathrm{V}-\mathrm{C}$, and one was detected between V-A and V-B (data not shown).

\section{Discussion}

Here we identified a set of diagnostic markers for species identification in the commercially and recreationally important sunset and vermilion rockfishes. Additionally, many of the RADseq markers generated for characterizing interspecific differentiation also provide powerful insight into the intraspecific population structure of both species and reveal dissimilar levels of differentiation. Specifically, vermilion rockfish exhibit much stronger signals of differentiation compared to the relatively weak but significant differentiation observed in sunset. Notably, introgressed sunset rockfish clearly group with conspecifics (i.e., nonintrogressed sunset rockfish) and show little evidence of admixture with vermilion, a clear delineation not possible using solely mitochondrial haplotype data. Within both species, the distinct genetic groups exhibit dissimilar geographic distributions that appear correlated to latitude and/or bathymetry. Notably, both species have a distinct genetic group on the Southern California Shelf.

\section{Interspecific differentiation patterns}

Genome-wide RADseq markers clearly distinguish between sunset and vermilion rockfishes in all interspecific analyses. Wright's fixation index between the sister species is similar to that reported in other closely related Sebastes spp. (Benestan et al. 2020). However, we detected evidence of nuclear introgression, which includes an apparent $\mathrm{F} 1$ hybrid (that was previously identified as an indeterminate hybrid), several possible back crosses, as well as individuals with lower levels of introgression (Fig. 2). Interestingly, the direction of introgression appeared disproportionate with more evidence of sunset introgression into vermilion. Previous genetic work in the sister species using microsatellites, however, suggested low levels of bidirectional nuclear admixture (Hyde et al. 2008a, b). 


\section{Differences in intraspecific population differentiation}

Sunset rockfish exhibit weak but significant population genetic differentiation (Table 1) between two groups with dissimilar geographic distributions which is a novel finding. Specifically, sunset individuals in group S-A are restricted to near shore habitat in the northern portion of the range down to approximately Dana Point and are conspicuously missing from the offshore banks and islands of the Southern California Shelf, except for Catalina Island (Fig. 5). Interestingly, a similar geographic distribution was observed for highly differentiated populations of cowcod (Sebastes levis), although the mechanisms driving the differentiation and distribution were unknown (Hess et al. 2014). The near equal ratio of introgressed to non-introgressed sunset rockfish in both groups demonstrates that mitochondrial haplotypes are not correlated with this pattern of differentiation. Depth, however, may contribute to the observed intraspecific differentiation as the two groups exhibit dissimilar depth distributions (Fig. S1A). Indeed, segregation by depth has played a significant role in the differentiation of closely related Sebastes spp. and the diversity of rockfishes as a whole (Heras and Aguilar 2019; Hyde et al. 2008a, b; Hyde and Vetter 2007; Ingram 2011; Love et al. 2002). However, the possible relationship between depth and the distribution of S-A and S-B genetic groups observed here could be a sampling artifact. Planned work to disentangle the thousands of nominal vermilion rockfish samples, and associated metadata, may yield additional sunset rockfish data that would allow for a more robust investigation into this potential relationship. Undoubtedly, subsequent population genomic work on sunset rockfish should include samples where S-A and S-B overlap (i.e., Point Conception), allowing for more detailed investigations into potential mechanisms behind the apparent differences in depth distribution. Similar distribution patterns have been attributed to factors such as ecological competition and life history differences in other Sebastes spp. (Hyde et al. 2008a, b; Ingram 2011; Larson 1980).

Vermilion rockfish display an order of magnitude stronger signal of population genetic differentiation and are instead characterized by three distinct groups with latitudinally stratified distributions (Table 1, Fig. 8). Inference into whether depth distribution differs amongst the vermilion genetic groups is not possible here as we lack depth data for V-A and V-B individuals. However, as discussed in the previous paragraph, future diagnostic work on the thousands of nominal vermilion rockfish individuals may allow for insight into this question. Group V-C dominates south of Point Conception, which was previously identified as a strong genetic break for this species (Budrick 2016; Hyde and Vetter 2009) and many other taxa, including other Sebastes spp. (Briggs 1974; Buonaccorsi et al. 2004, 2005; Pelc et al. 2009). The observed pattern of progressively decreasing $\mathrm{H}_{\mathrm{S}}$ moving from the southernmost group $(\mathrm{V}-\mathrm{C})$ poleward to the northernmost group (V-A) suggests that V-C, with the highest observed diversity, may represent the ancestral population. It follows that V-B would have differentiated from V-C in an expansion north, with a third poleward expansion of V-A subsequently differentiating from $\mathrm{V}-\mathrm{B}$. This pattern, along with the pairwise $\mathrm{F}_{\mathrm{ST}}$ comparisons, corroborates a steppingstone pattern of gene flow for vermilion rockfish, as previously suggested (Budrick 2016; Hyde and Vetter 2009). However, gene flow amongst these distinct genetic groups appears to be fairly low in general based on the strong pairwise $\mathrm{F}_{\mathrm{ST}}$ comparisons (including fixed differences between $\mathrm{V}-\mathrm{A} / \mathrm{V}-\mathrm{C}$ and V-A/V-B) and significant differences in $\mathrm{H}_{\mathrm{S}}$ between all group comparisons. Indeed, the degree of divergence between vermilion rockfish groups is similar to levels of interspecific differentiation observed between sister Sebastes species, such as the gopher rockfish and black and yellow rockfish (Narum et al. 2004) as well as the blue rockfish and deacon rockfish (Burford and Bernardi 2008). The central coast of California harbors all three distinct vermilion genetic groups, corroborating the observation from Hyde and Vetter (2009) that the highest vermilion diversity exists in this area. Given that adults of all three genetic groups overlap in this region, the potential for inter-group breeding appears highly plausible. Although limited larval dispersal due to parturition timing in conjunction with the seasonal prevailing oceanographic conditions is thought to restrict gene flow amongst regions in vermilion rockfish (Hyde and Vetter 2009), this scenario would not produce a barrier for these apparently sympatric genetic groups. Notably we did detect an apparent hybrid between V-B and V-C groups that suggests interbreeding between groups does occur. However, based on the otherwise strong differentiation patterns, it appears that a barrier to gene flow exists. One potential explanation could be assortative mating, a potentially strong barrier to gene flow. Indeed, Sebastes rockfishes are viviparous with internal fertilization and courtship displays have been characterized in other Sebastes spp. (Helvey 1982; Shinomiya and Ezaki 1991), suggesting mate selection. Further work is required to better understand this strong intra-specific differentiation in vermilion rockfish.

Distinct life history behaviors may contribute to the dissimilar levels of intraspecific differentiation observed in sunset and vermilion rockfish. The weaker intraspecific differentiation characterizing sunset rockfish could be explained by increased connectivity through ontogenetic migration of juveniles to offshore banks and deeper habitat suitable for adults. Canary rockfish, S. pinniger - the sister taxon to the sunset and vermilion rockfish clade-share a similar ontogenetic migration of juveniles to adult habitat (Vetter and Lynn 1997), which is common in Sebastes spp. (Love et al. 1991), and do not exhibit any significant population 
structure (Andrews et al. 2018; Budrick 2016). Whereas vermilion rockfish, which show strong intraspecific differentiation, may have restricted gene flow due to the lack of this ontogenetic shift, in conjunction with strong biogeographic barriers in its range as suggested by Hyde and Vetter (2009). Specifically, because there is little movement as juveniles or adults, the larval stage is the most likely method of dispersal, which can be greatly affected by prevailing currents, upwelling, and offshore jet (Leis 1991). The absence of an ontogenetic migration is also implicated for precipitating the divergence between sunset and vermilion roughly $2.3 \mathrm{Ma}$ (Hyde et al. 2008a, b; Hyde and Vetter 2007). Interestingly, we find that both sunset and vermilion rockfish show a pattern of intraspecific variation where a single genetic group dominates the offshore banks and islands of the Southern California Shelf. The eddies around the islands and the gyre of prevailing circulation that characterize the Southern California Bight (Bray et al. 1999) may affect larval dispersal patterns but additional samples and work is needed to properly assess this possibility.

Because the underlying purpose of generating these RADseq data was to identify and characterize candidate markers for a diagnostic SNP panel, our intraspecific analyses are limited by relatively small sample sizes. A robust sunset population genetic study that includes more samples, especially from the southern portion of the range is warranted based on the observed structure with this limited dataset. The population genetic structure of vermilion has already been thoroughly evaluated (Budrick 2016; Hyde and Vetter 2009), although further insight into the distribution of the three observed clusters in this study at the periphery of the range could be useful for management purposes. Additionally, focused sampling of vermilion rockfish in Central California from Cape Mendocino to Point Conception, where all three groups co-occur, could shed light on the degree of overlap in depth distributions. This would allow clearer insight into the potential mechanisms restricting gene flow in this region of overlap and further our understanding of the processes driving differentiation in the highly speciose Sebastes rockfishes.

\section{Fisheries management implications}

Although the cryptic sunset rockfish was identified over a decade ago (Hyde et al. 2008a, b), this distinct species is still managed collectively with vermilion rockfish as a single species. Managing multiple, discrete stocks as one ostensibly homogeneous population may result in an increased risk of overfishing to one or more of the stocks or the inadvertent (and potentially undiagnosed) loss of genetic diversity if the spatial distribution of fishing effort is misaligned with the population's underlying stock structure (Hauser et al. 2002; Kerr et al. 2017; Laikre et al. 2005; Okamoto et al.
2019; Spies and Punt 2015; Sterner 2007). Given the current management regime, these and other potential risks to this species pair have not been evaluated which is a significant concern for such an economically and ecologically important assemblage.

This research also furthers our knowledge of the degree of intraspecific genetic structure characterizing each species, which should also be accounted for in an effective management strategy (Reiss et al. 2009; Spies and Punt 2015; Waples et al. 2008). Our findings suggest weak but significant intraspecific differentiation for sunset rockfish, however our sampling was relatively limited and a thorough population genetic study is warranted to better characterize this structure. Although more data are required, our results provide no clear indication of distinct management needs for these genetic groups. Vermilion rockfish, however, show relatively strong signals of differentiation that appear to be correlated with latitude. In California, the vermilion rockfish species complex has historically been managed with boundaries at Cape Mendocino and/or Point Conception, which generally match our findings of where the genetic breaks occur. Specifically, V-A is the only group found north of Cape Mendocino, V-B predominantly occurs between Cape Mendocino and Point Conception, while V-C dominates to the south of Point Conception. Therefore, these management boundaries which have been used for the species complex may be ideal boundaries for vermilion rockfish as suggested by Hyde and Vetter (2009).

This effort's next step is to use the diagnostic SNPs described here to delineate to species $\sim 25,000$ nominal vermilion rockfish samples collected during previous NWFSC Southern California Shelf Rockfish Hook and Line and West Coast Groundfish Bottom Trawl Surveys. Separating these existing samples will support finer resolution of the differences in spatial and depth distribution between the two species as well as comparisons of their respective age and growth, reproductive biology, and diet and trophic patterns. It will also provide much needed insight into both interspecific differentiation as well as intraspecific population genetic structure. These analyses will help inform decisions about whether the two species are most appropriately assessed and managed collectively or individually and ensure the PFMC has the best information possible to reduce the risk of overfishing to both components of this valuable fishery.

Supplementary Information The online version contains supplementary material available at https://doi.org/10.1007/s10592-021-01397-4.

Author contributions GCL and KMN designed the study with input from all authors. Samples were provided by JH, JRH, and MTC, GCL and AR conducted the lab work. Analyses were performed by GCL. The first draft of the manuscript was written by GCL and all authors commented on and edited subsequent versions of the manuscript. 
Funding This work was funded by the Saltonstall-Kennedy Grant (Proposal \# 20WCR010-020).

Data availability Demultiplexed and quality-filtered RADseq data are available at NCBI Sequence Read Archive (SRA) with Accession Number PRJNA721730.

\section{Declarations}

Conflict of interest The authors declare no conflict of interest or competing interests.

Informed consent All authors read and approved the final manuscript.

Research involving animal rights Tissue samples were collected from the National Marine Fisheries Service West Coast Groundfish Bottom Trawls and Hook and Line Surveys or opportunistically from fish markets.

Open Access This article is licensed under a Creative Commons Attribution 4.0 International License, which permits use, sharing, adaptation, distribution and reproduction in any medium or format, as long as you give appropriate credit to the original author(s) and the source, provide a link to the Creative Commons licence, and indicate if changes were made. The images or other third party material in this article are included in the article's Creative Commons licence, unless indicated otherwise in a credit line to the material. If material is not included in the article's Creative Commons licence and your intended use is not permitted by statutory regulation or exceeds the permitted use, you will need to obtain permission directly from the copyright holder. To view a copy of this licence, visit http://creativecommons.org/licenses/by/4.0/.

\section{References}

Ali OA, O’Rourke SM, Amish SJ, Meek MH, Luikart G, Jeffres C, Miller MR (2016) RAD capture (rapture): flexible and efficient sequence-based genotyping. Genetics 202:389-400. https://doi. org/10.1101/028837

Andrews KS, Nichols KM, Elz A, Tolimieri N, Harvey CJ, Pacunski $\mathrm{R}$, Tonnes DM (2018) Cooperative research sheds light on population structure and listing status of threatened and endangered rockfish species. Conserv Genet 19(4):865-878. https://doi.org/ 10.1007/s10592-018-1060-0

Benestan L, Rougemount Q, Senay C, Normandeau E, Parent E, Rideout R, Parent GJGJ (2020) Population genomics and history of speciation reveal fishery management gaps in two related redfish species (Sebastes mentella and Sebastes fasciatus). Evolut Appl. https://doi.org/10.1111/eva.13143

Bernatchez L, Wellenreuther M, Araneda C, Ashton DT, Barth JMI, Beacham TD, Withler RE (2017) Harnessing the power of genomics to secure the future of seafood. Trends Ecol Evol 32(9):665680. https://doi.org/10.1016/j.tree.2017.06.010

Bohling J, Small M, Von Bargen J, Louden A, DeHaan P (2019) Comparing inferences derived from microsatellite and RADseq datasets: a case study involving threatened bull trout. Conserv Genet 20(2):329-342. https://doi.org/10.1007/s10592-018-1134-z

Bradbury IR, Laurel B, Snelgrove PVR, Bentzen P, Campana SE (2008) Global patterns in marine dispersal estimates: the influence of geography, taxonomic category and life history. Proc R Soc B 275(1644):1803-1809. https://doi.org/10.1098/rspb.2008.0216
Bray NA, Keyes A, Morawitz WML (1999) The California current system in the Southern California Bight and the Santa Barbara Channel. J Geophys Res 104(C4):7695-7714. https://doi.org/10. 1029/1998jc900038

Briggs JC (1974) Marine zoogeography. McGraw-Hill, New York

Budrick, J. E. (2016). Evolutionary processes contributing to population structure in the rockfishes of the Subgenus Rosicola: implications for Fishery Management, stock assessment and prioritization of future analyses of structure in the Genus Sebastes. University of California, Berkeley

Buonaccorsi VP, Westerman M, Stannard J, Kimbrell C, Lynn E, Vetter RD (2004) Molecular genetic structure suggests limited larval dispersal in grass rockfish, Sebastes Rastrelliger. Mar Biol 145(4):779-788. https://doi.org/10.1007/s00227-004-1362-2

Buonaccorsi VP, Kimbrell CA, Lynn EA, Vetter RD (2005) Limited realized dispersal and introgressive hybridization influence genetic structure and conservation strategies for brown rockfish, Sebastes Auriculatus. Conserv Genet 6(5):697-713. https://doi. org/10.1007/s10592-005-9029-1

Burford MO, Bernardi G (2008) Incipient speciation within a subgenus of rockfish (Sebastosomus) provides evidence of recent radiations within an ancient species flock. Mar Biol 154(4):701-717. https:// doi.org/10.1007/s00227-008-0963-6

Burford MO, Carr MH, Bernardi G (2011) Age-structured genetic analysis reveals temporal and geographic variation within and between two cryptic rockfish species. Mar Ecol Prog Ser 442:201-215. https://doi.org/10.3354/meps09329

Campbell NR, Harmon SA, Narum SR (2015) Genotyping-in-Thousands by sequencing (GT-seq): a cost effective SNP genotyping method based on custom amplicon sequencing. Mol Ecol Resour 15(4):855-867. https://doi.org/10.1111/1755-0998.12357

Catchen J, Hohenlohe PA, Bassham S, Amores A, Cresko WA (2013) Stacks: an analysis tool set for population genomics. Mol Ecol 22(11):12354. https://doi.org/10.1111/mec.12354

Conrath CL (2017) Maturity, spawning omission, and reproductive complexity of deepwater rockfish. Trans Am Fish Soc 146(3):495-507. https://doi.org/10.1080/00028487.2017.1285352

Danecek P, Auton A, Abecasis G, Albers CA, Banks E, DePristo MA Durbin R (2011) The variant call format and VCFtools. Bioinformatics 27(15):2156-2158. https://doi.org/10.1093/bioinforma tics/btr330

DeWoody JA, Avise JC (2000) Microsatellite variation in marine, freshwater and anadromous fishes compared with other animals. J Fish Biol 56(3):461-473. https://doi.org/10.1006/jfbi.1999.1210

Earl DA, vonHoldt BM (2012) STRUCTURE HARVESTER: a website and program for visualizing STRUCTURE output and implementing the Evanno method. Conserv Genet Resour 4(2):359-361. https://doi.org/10.1007/s12686-011-9548-7

Evanno G, Regnaut S, Goudet J (2005) Detecting the number of clusters of individuals using the software STRUCTURE: a simulation study. Mol Ecol 14(8):2611-2620. https://doi.org/10.1111/j.1365294X.2005.02553.x

Frable BW, Wolfe Wagman D, Frierson TN, Aguilar A, Sidlauskas BL (2015) A new species of Sebastes (Scorpaeniformes:Sebastidae) from the northeastern Pacific, with a redescription of the blue rockfish, S. mystinus (Jordan and Gilbert, 1881). Fish Bull 113(4):355-377. https://doi.org/10.7755/FB.113.4.1

Gaither MR, Coker DJ, Greaves S, Sarigol F, Payet SD, Chaidez V, Berumen ML (2020) Does color matter? Molecular and ecological divergence in four sympatric color morphs of a coral reef fish. Ecol Evol. https://doi.org/10.1002/ece3.6566

Gharrett AJ, Matala AP, Peterson EL, Gray AK, Li Z, Heifetz J (2005) Two genetically distinct forms of Rougheye rockfish are different species. Trans Am Fish Soc 134(1):242-260. https://doi.org/10. 1577/t04-055.1 
Goudet J (2005) HIERFSTAT, a package for R to compute and test hierarchical F-statistics. Mol Ecol Notes 5:184-186. https://doi. org/10.1111/j.1471-8278

Harms JH, Benante JA, Barnhart RM, Commerce U. S. D. of, \& Administration, N. O. and A (2008) The 2004-2007 Hook and line survey of shelf rockfish in the Souther California bight: estimates of distribution, abundance, and length composition. U.S. Dept. Commer., NOAA Tech. Memo. NMFS-NWFSC-95

Hauser L, Seeb JE (2008) Advances in molecular technology and their impact on fisheries genetics. Fish Fish 9(4):473-486. https://doi. org/10.1111/j.1467-2979.2008.00306.x

Hauser L, Adcock GJ, Smith PJ, Ramírez JHB, Carvalho GR (2002) Loss of microsatellite diversity and low effective population size in an overexploited population of New Zealand snapper (Pagrus auratus). Proc Natl Acad Sci USA 99(18):11742-11747. https:// doi.org/10.1073/pnas.172242899

Helvey M (1982) First observations of courtship behavior in rockfish, genus Sebastes. Copeia 1982(4):763. https://doi.org/10.2307/ 1444084

Heras J, Aguilar A (2019) Comparative transcriptomics reveals patterns of adaptive evolution associated with depth and age within marine rockfishes (Sebastes). J Hered 110(3):340-350. https://doi.org/10. 1093/jhered/esy070

Hess JE, Chittaro P, Elz A, Gilbert-Horvath EA, Simon V, Garza JC, Morán P (2014) Cryptic population structure in the severely depleted cowcod, Sebastes levis. Can J Fish Aquat Sci 71(1):8192. https://doi.org/10.1139/cjfas-2012-0510

Hyde JR, Vetter RD (2007) The origin, evolution, and diversification of rockfishes of the genus Sebastes (Cuvier). Mol Phylogenet Evol 44(2):790-811. https://doi.org/10.1016/j.ympev.2006.12.026

Hyde JR, Vetter RD (2009) Population genetic structure in the redefined vermilion rockfish (Sebastes miniatus) indicates limited larval dispersal and reveals natural management units. Can J Fish Aquat Sci 66:1569-1581. https://doi.org/10.1139/F09-104

Hyde JR, Kimbrell CA, Budrick JE, Lynn EA, Vetter RD (2008a) Cryptic speciation in the vermilion rockfish (Sebastes miniatus) and the role of bathymetry in the speciation process. Mol Ecol 17(4):1122-1136. https://doi.org/10.1111/j.1365-294X.2007. 03653.x

Hyde JR, Kimbrell C, Robertson L, Clifford K, Lynn E, Vetter R (2008b) Multiple paternity and maintenance of genetic diversity in the live-bearing rockfishes Sebastes spp. Mar Ecol Prog Ser 357:245-253. https://doi.org/10.3354/meps07296

Ingram T (2011) Speciation along a depth gradient in a marine adaptive radiation. Proc R Soc B 278(1705):613-618. https://doi.org/10. 1098/rspb.2010.1127

Jakobsson M, Rosenberg NA (2007) CLUMPP: a cluster matching and permutation program for dealing with label switching and multimodality in analysis of population structure. Bioinformatics 23(14):1801-1806. https://doi.org/10.1093/bioinformatics/ btm233

Johns GC, Avise JC (1998) Tests for ancient species flocks based on molecular phylogenetic appraisals of Sebastes rockfishes and other marine fishes. Evolution 52(4):1135-1146

Jombart T (2008) Adegenet: a R package for the multivariate analysis of genetic markers. Bioinformatics 24(11):1403-1405. https://doi. org/10.1093/bioinformatics/btn129

Jombart T, Devillard S, Balloux F, Falush D, Stephens M, Pritchard J, Nei M (2010) Discriminant analysis of principal components: a new method for the analysis of genetically structured populations. BMC Genet 11(1):94. https://doi.org/10.1186/1471-2156-11-94

Keller AA, Wallace JR, Methot RD (2017). The Northwest Fisheries science center's west coast groundfish bottom trawl survey: history, design, and description. U.S. Department of Commerce, NOAA Tech. Memo. NMFS-NWFSC-136. https://doi.org/10. 7289/V5/TM-NWFSC-136
Kerr LA, Hintzen NT, Cadrin SX, Clausen LW, Dickey-Collas M, Goethel DR, Nash RDM (2017) Lessons learned from practical approaches to reconcile mismatches between biological population structure and stock units of marine fish. ICES J Mar Sci 74(6):1708-1722. https://doi.org/10.1093/icesjms/fsw188

Laikre L, Palm S, Ryman N (2005) Genetic population structure of fishes: implications for coastal zone management. Ambio 34(2):111-119. https://doi.org/10.1579/0044-7447-34.2.111

Larson RJ (1980) Competition, habitat selection, and the bathymetric segregation of two rockfish (Sebastes) species. Ecol Soc Am 50(2):221-239

Larson WA, Seeb LW, Everett MV, Waples RK, Templin WD, Seeb JE (2014) Genotyping by sequencing resolves shallow population structure to inform conservation of Chinook salmon (Oncorhynchus tshawytscha). Evol Appl 7(3):355-369. https://doi.org/10. 1111/eva.12128

Leis JM (1991) The pelagic stage of reef fishes. In: Sale P (ed) The ecology of fishes on coral reefs. Academic Press Inc, San Diego, pp 182-229

Longo GC, Lam L, Basnett B, Samhouri J, Hamilton S, Andrews K, Nichols KM (2020) Strong population differentiation in lingcod (Ophiodon elongatus) is driven by a small portion of the genome. Evolut Appl. https://doi.org/10.1111/eva.13037

Love MS, Passarelli JK (2020) Miller and lea's guide to the coastal marine fishes of California, 2nd edn. UC Argriculture and Natural Resources Publication, Davis, p 3556

Love MS, Carr MH, Haldorson LJ (1991) The ecology of substrateassociated juveniles of the genus Sebastes. In: Boehlert GW, Yamada J (eds) Developments in environmental biology of fishes, vol 11. Springer, Dordrecht. https://doi.org/10.1007/978-94-0113792-8_21

Love, M. S., Yoklavich, M., \& Thorsteinson, L. (2002). The rockfishes of the northeast Pacific. U. of C. Press, ed., Berkeley

Lovell SK, Hilger J, Steinback S, Hutt C (2016) The Economic Contribution of Marine Angler Expenditures on Durable Goods in the United States, 2014. Accessed http://spo.nmfs.noaa.gov/tm/ or http://www.st.nmfs.noaa.gov/economics/index

Martinez AS, Willoughby JR, Christie MR (2018) Genetic diversity in fishes is influenced by habitat type and life-history variation. Ecol Evol 8(23):12022-12031. https://doi.org/10.1002/ece3.4661

McKinney GJ, Pascal CE, Templin WD, Gilk-Baumer SE, Dann TH, Seeb LW, Seeb JE (2020) Dense SNP panels resolve closely related chinook salmon populations. Can J Fish Aquat Sci 77(3):451-461. https://doi.org/10.1139/cjfas-2019-0067

Morgan TD, Graham CF, McArthur AG, Raphenya AR, Boreham DR, Manzon RG, Somers CM (2018) Genetic population structure of the round whitefish (Prosopium cylindraceum) in North America: multiple markers reveal glacial refugia and regional subdivision. Can J Fish Aquat Sci 75(6):836-849. https://doi.org/10.1139/ cjfas-2016-0528

Narum SR, Buonaccorsi VP, Kimbrell CA, Vetter RD (2004) Genetic divergence between gopher rockfish (Sebastes carnatus) and black and yellow rockfish (Sebastes chyrsomelas). Copeia 2004(4):926-931

Okamoto DK, Hessing-Lewis M, Samhouri JF, Shelton AO, Stier A, Levin PS, Salomon AK (2019) Spatial variation in exploited metapopulations obscures risk of collapse. Ecol Appl. https://doi.org/ 10.1002/eap.2051

Orr JW, Hawkins S (2008) Species of the rougheye rockfish complex: resurrection of Sebastes melanostictus (Matsubara, 1934) and a redescription of Sebastes aleutianus (Jordan and Evermann, 1898) (Teleostei: Scorpaeniformes). Fish Bull 106(2):111-134

Pante E, Simon-Bouhet B (2013) marmap: a package for importing, plotting and analyzing bathymetric and topographic data in R. PLoS ONE 8(9):e73051. https://doi.org/10.1371/journal.pone. 0073051 
Paris JR, Stevens JR, Catchen JM (2017) Lost in parameter space: a road map for STACKS. Methods Ecol Evol. https://doi.org/10. 1111/2041-210X.12775

Pelc RA, Warner RR, Gaines SD (2009) Geographical patterns of genetic structure in marine species with contrasting life histories. J Biogeogr 36(10):1881-1890. https://doi.org/10.1111/j.13652699.2009.02138.x

Pritchard JK, Stephens M, Donnelly P (2000) Inference of population structure using multilocus genotype data. Genetics 155(2):945-959

Reiss H, Hoarau G, Dickey-Collas M, Wolff WJ (2009) Genetic population structure of marine fish: mismatch between biological and fisheries management units. Fish Fish 10:361-395

Rochette NC, Catchen JM (2017) Deriving genotypes from RADseq short-read data using Stacks. Nat Protoc 12(12):2640-2659. https://doi.org/10.1038/nprot.2017.123

Romiguier J, Gayral P, Ballenghien M, Bernard A, Cahais V, Chenuil A, Galtier N (2014) Comparative population genomics in animals uncovers the determinants of genetic diversity. Nature 515(7526):261-263. https://doi.org/10.1038/nature13685

Shinomiya A, Ezaki O (1991) Mating habits of the rockfish Sebastes inermis. In: Boehlert GW, Yamada J (eds) Developments in environmental biology of fishes, vol 11. Springer, Dordrecht. https:// doi.org/10.1007/978-94-011-3792-8_2

Spies I, Punt AE (2015) The utility of genetics in marine fisheries management: a simulation study based on Pacific cod off Alaska. Can J Fish Aquat Sci 72(9):1415-1432. https://doi.org/10.1139/ cjfas-2014-0050

Sterner T (2007) Unobserved diversity, depletion and irreversibility: the importance of subpopulations for management of cod stocks.
Ecol Econ 61(2-3):566-574. https://doi.org/10.1016/j.ecolecon. 2006.05.015

Vaux F, Bohn S, Hyde JR, O’Malley KG (2021) Adaptive markers distinguish North and South Pacific Albacore amid low population differentiation. Evolut Appl. https://doi.org/10.1111/eva.13202

Vendrami DLJ, De Noia M, Telesca L, Handal W, Charrier G, Boudry P, Hoffman JI (2019) RAD sequencing sheds new light on the genetic structure and local adaptation of European scallops and resolves their demographic histories. Sci Rep 9(1):1-13. https:// doi.org/10.1038/s41598-019-43939-4

Vetter RD, Lynn EA (1997) Bathymetric demography, enzyme activity patterns, and bioenergetics of deep-living scorpaenid fishes (genera Sebastes and Sebastolobus): paradigms revisited. Mar Ecol Prog Ser 155:173-188. https://doi.org/10.3354/meps155173

Waples RS, Punt AE, Cope JM (2008) Integrating genetic data into management of marine resources: how can we do it better? Fish Fish 9(4):423-449. https://doi.org/10.1111/j.1467-2979.2008. 00303.x

Weir BS, Cockerham CC (1984) Estimating F-statistics for the analysis of population structure. Evolution 38(6):1358-1370. https://doi. org/10.2307/2409936

Wickham H (2016) ggplot2: elegant graphics for data analysis. Springer, New York

Publisher's Note Springer Nature remains neutral with regard to jurisdictional claims in published maps and institutional affiliations. 